\title{
Evaluation of the implementation of multidisciplinary fast-track program for acute geriatric hip fractures at a University Hospital in resource-limited settings
}

Unchana Sura-amonrattana ${ }^{1}$, Theerawoot Tharmviboonsri², Aasis Unnanuntana ${ }^{2}$, Direk Tantigate ${ }^{2}$ and Varalak Srinonprasert ${ }^{1 *}$

\begin{abstract}
Background: Hip fractures are common among frail, older people and associated with multiple adverse outcomes, including death. Timely and appropriate care by a multidisciplinary team may improve outcomes. Implementing a team to jointly deliver the service in resource-limited settings is challenging, particularly on the effectiveness of patient outcomes.

Methods: A retrospective cohort study to compare outcomes of hip fracture patients aged 65 or older admitted at Siriraj hospital before and after implementation of the Fast-track program for Acute Geriatric Hip Fractures. The primary outcome was the incidence of medical complications. The secondary outcomes were time to surgery, factors related to the occurrence of various complications, in-hospital mortality, and mortality at month 3, month 6 and month 12 after the operation.

Results: Three hundred two patients were enrolled from the Siriraj hospital's database from October 2016 to October 2018; 151 patients in each group with a mean age of 80 years were analyzed. Clinical parameters were similar between groups except the Fast-track group comprising more patients with dementia (37.1\% VS 23.8\%, $p<$ 0.012). In the Fast-track group, there was a significantly higher proportion of patients underwent surgery within 72 $\mathrm{h}(80.3 \%$ VS $44.7 \%, p<0.001)$ and the length of stay was significantly shorter ( 11 days (8-17) VS 13 days (9-18), $p=$ 0.017). There was no significant difference in medical complications. Stratified analysis by dementia status showed a trend in delirium reduction in both patients with dementia and without dementia groups, and a pressure injury reduction among patients with dementia after the program was implemented but without statistical significance. There was no significant difference in mortality.

Conclusions: The implementation of a multidisciplinary team for hip fracture patients is feasible in resource-limited setting. In the Fast-track program, time to surgery was reduced and the length of stay was shortened. Other outcome benefits were not shown, which may be due to incomplete uptake of all involved disciplines.
\end{abstract}

Keywords: Hip fracture, Orthogeriatric, Elderly, Dementia, Delirium, Complications, Length of stay, Mortality

* Correspondence: varalaksi@gmail.com

'Department of Medicine, Division of Geriatric Medicine, Faculty of Medicine

Siriraj Hospital, Mahidol University, Bangkok, Thailand

Full list of author information is available at the end of the article

C The Author(s). 2021 Open Access This article is licensed under a Creative Commons Attribution 4.0 International License, which permits use, sharing, adaptation, distribution and reproduction in any medium or format, as long as you give appropriate credit to the original author(s) and the source, provide a link to the Creative Commons licence, and indicate if changes were made. The images or other third party material in this article are included in the article's Creative Commons licence, unless indicated otherwise in a credit line to the material. If material is not included in the article's Creative Commons licence and your intended use is not permitted by statutory regulation or exceeds the permitted use, you will need to obtain permission directly from the copyright holder. To view a copy of this licence, visit http://creativecommons.org/licenses/by/4.0/. The Creative Commons Public Domain Dedication waiver (http://creativecommons.org/publicdomain/zero/1.0/) applies to the data made available in this article, unless otherwise stated in a credit line to the data. 


\section{Background}

Hip fractures are common injuries that result in loss of function, reduction in quality of life, an increase in morbidity and mortality in older people [1, 2]. Globally, more than 4.5 million patients per year suffer from medical complications due to improper management of hip fractures. As society ages, post-hip fracture morbidity may affect up to 21 million persons in 2050 [3-6]. Male gender, older age, and multiple comorbidities are associated with an increased risk of death within the first year after a hip fracture [7]. In Thailand, there is an increase in the incidence of hip fractures in people aged 65 years old and older, which substantially increased short term and long term mortality.

Most hip fractures are more likely to occur in frail older people with several geriatric syndromes such as functional impairment, malnutrition and dementia [8, 9]. Consequently, those patients with complex medical comorbidities require more attention prior to undergoing operation. Moreover, they are more likely to be at risk of postoperative complications and prolonged hospital stays with their pre-morbid complexity. Multiple studies [9-26] have reported that factors such as proper care at presentation, optimal pain control, an orthogeriatric model of care, comprehensive geriatric assessment (CGA), expedited time to surgery and early rehabilitation are associated with a lower risk of complications and decreased mortality in older patients with hip fractures.

Thailand is a middle-income country where proportion of older people has risen rapidly, reaching $18 \%$ of the population in 2021 [27]. However, the number of health care personnel specialized for taking care of older people is limited [28-30]. Allocation of human resources and operating rooms for the multidisciplinary care team for non-emergency condition such as hip fracture is challenging in resource-limited settings. After the existing literature had been reviewed [31-34] showing sparse evidence from resource limited settings, a multidisciplinary program titled "Acute Geriatric Hip Fracture: Fast Track in Siriraj Hospital" was initiated for older patients with hip fractures in September 2017. Initially, the team composed of orthopedic trauma team, geriatricians, anesthesiologists, physical therapists and nurse coordinators attempted to contemplate the flow for patient care according to international practice guidelines. The structure, process and outcome quality indicators in Table 1 have been set and continuously monitored through quarterly meetings. The primary target of the service team was to reduce the time to surgery, while the ultimate goal was to improve patients' outcomes. The purpose of this study was to evaluate patient outcomes before and after implementation of the Fast-track program for Acute Geriatric Hip Fractures. The primary outcome was the incidence of medical complications. The secondary outcomes were time to surgery, causes of delayed surgery, short term and long term morbidity and short term and long term mortality.

\section{Methods}

\section{Study design and data collection}

All patients with hip fractures admitted to the Department of Orthopedics, Siriraj Hospital, Thailand, from October 2016 to October 2018 were identified retrospectively from the Siriraj hospital's database. The database comprised medical records from inpatient and outpatient services. For inpatient documents, all progress notes documented by the multidisciplinary team were

Table 1 The structure, process and outcome quality indicators for the implementation of the Fast-track program for Acute Geriatric Hip Fractures

\begin{tabular}{ll}
\hline Structure quality indicators & Orthogeriatric management during admission \\
& Using an agreed multidisciplinary protocol \\
& Hip fracture surgery planned on an operation list \\
Process quality indicators & Assessed by a geriatrician within 24 $\mathrm{h}$ \\
& Assessed by the Acute Pain Service (APS) within 24 $\mathrm{h}$ \\
& Immediate analgesia on presentation and in case of pain \\
& Time to surgery within 72 $\mathrm{h}$ \\
Outcome quality indicators & Early ambulation after surgery \\
& Intraoperative adverse events \\
& Postoperative major medical complications \\
& Re-operation rate \\
& Length of hospital stay \\
In-hospital mortality, 3-month mortality, 6-month mortality, 1-year mortality \\
Discharge destination \\
\hline
\end{tabular}


collected. The database also included electronic laboratory data and image data. The admitted hip fracture patients aged 65 years or older with complete medical records were selected to be the subjects for the study. Patients who underwent elective surgery were excluded, and then the included population were divided into the PRE-fast track group and the Fast-track one according to the time of the program implementation.

Medical records were retrieved according to the ICD-9,10 (International Classification of Diseases 910th Revision) diagnostic codes for hip fracture (820.0-820.9 and S720-S722). Among 905 medical records identified, 803 patients aged $\geq 65$ years meeting inclusion criteria were included (Fig. 1). After having initially reviewed, medical records were sorted, according to the admission number (AN) for both the PRE-fast track group and the Fast-track one. Then, we started to review forward according to the admission number in the Fast-track group and backward in the PRE-fast track group from the day of the starting program until the sample size target was met.

All relevant medical records were reviewed to identify patients' medical comorbidities, premorbid functional status, interventions and complications occurring during hospitalization. With respect to delirium, the detection of delirium was performed by a clinical trainee in geriatric medicine. The patient was determined to have delirium if the medical record contained any document representing awareness of the syndrome, progress notes describing delirium or confusion, notes attempting to identify the causes of delirium, or notes describing any treatment to control delirium symptoms. Discharge summaries were also reviewed to identify any document of the signs and delirium symptoms.

Beginning in July 2016, all hip fracture patients admitted to orthopedic wards were recruited in the Siriraj Fracture Liaison Service (FLS). Patients in the FLS registry were followed from hospital admission until

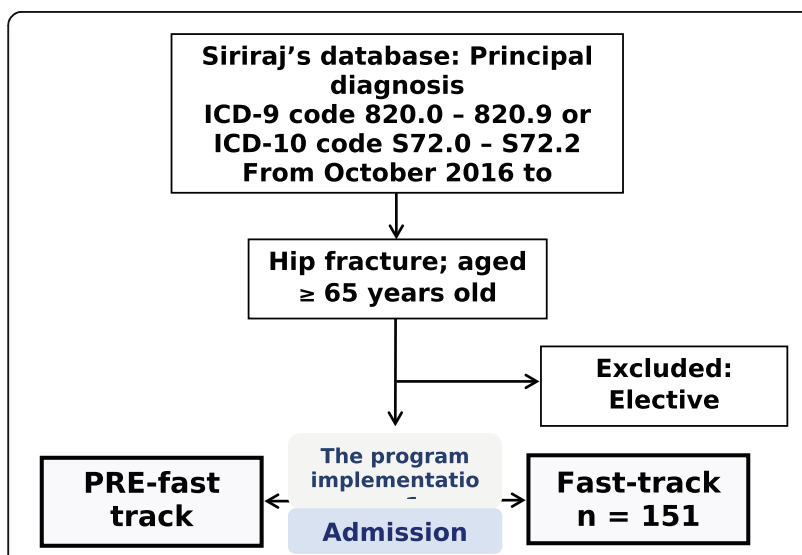

Fig. 1 Subject selection flow chart discharge and subsequent visits. Information regarding mortality and functional outcomes was obtained through electronic hospital records and data from the FLS registry.

\section{PRE- the fast-track program for acute geriatric hip fractures (PRE-fast track program)}

The orthopedic trauma team was responsible for the standard hip fracture treatment including pain control, basic preoperative assessment and scheduled surgery time. Surgery would be performed according to the availability of operative rooms and surgeons' regular work schedules. Consultation with the on-call medical teams and the geriatric team was available on request. Physical therapists assessed the patients when they were admitted to the orthopedic ward, but there was no standard protocol on mobilization or postoperative medical management (Table 2).

\section{The fast-track program for acute geriatric hip fractures (fast-track program)}

The Fast-track model is a multidisciplinary team of medical specialists and allied health teams including orthopedists, geriatricians, anesthesiologists, physical therapists and nurse coordinators. The Fast-track care commences on admission to the hospital. The role of each discipline in the team and assessment timeframe were assigned in the protocol. Acute pain service (APS), operated by anesthesiologists, aims to optimize pain control within the first $24 \mathrm{~h}$ by providing femoral nerve catheter blockade, and then customizing pain medications. Applying the orthogeriatric model of care as a framework, the geriatric team manages the patients within the first $24 \mathrm{~h}$ of admission until the patients were discharged from the hospital. Surgery is scheduled as quickly as possible, and spinal anesthesia is the preferable method. The Fast-track program aims to have all patients in the surgical operating room within $72 \mathrm{~h}$ of admission. An operating room is also dedicated for the hip fracture patients, which allows the patients to undergo surgery as planned. The program also aims to prevent medical complications (delirium, urinary tract infection, pressure injury, stroke, pulmonary embolism/ deep vein thrombosis, myocardial infarction), provide nutritional counseling and supplements, achieve at least a sitting position on the first postoperative day, and begin the discharge planning in the early period of care (Table 2).

\section{Outcomes}

The primary outcome was the incidence of medical complications. The secondary outcomes were the proportion of achieving the 72-h time-to-surgery target, causes of delayed surgery, in-hospital mortality, 
Table 2 Comparison of the PRE-fast track program and the Fast-track program for Acute Geriatric Hip Fractures (Fast-track program)

\begin{tabular}{ll}
\hline PRE-fast track program & Fast-track program \\
\hline - Managed by the orthopedic trauma team & - Reviewed by the orthopedic, geriatric and Acute Pain Service (APS) teams \\
- Admitted to the orthopedic wards & within $24 \mathrm{~h}$ of admission \\
- Consult on-call medical teams & - Admitted to the orthopedic wards \\
- Geriatric teams available on request & - Geriatric team review to optimize medical condition preoperative and \\
- Physical therapists assessed the patients when they were admitted to & monitor during admission \\
the orthopedic ward, but no a standard protocol on mobilization & - APS operated by anesthesiologists aims to optimize pain control within \\
& the first $24 \mathrm{~h}$ by providing femoral nerve catheter blockade \\
& - Surgery within $72 \mathrm{~h}$ required after admission \\
& - Physical therapists assessed the patient conditions on admission to the \\
& orthopedic ward; aimed to achieve at least a sitting position on the first \\
& postoperative day \\
\hline
\end{tabular}

mortality at month 3 , month 6 , month 12 after the surgery and function status (Barthel index) at postoperative day 4, month 3 and month 12 .

\section{Statistical analysis}

For the comparison between the patient outcomes of the PRE-fast track program and those of the Fast-track program, a sample size calculation was conducted by assuming the incidence of delirium in the conventional group of 53 and $37 \%$ in the intervention group [35]. With $80 \%$ power and a 5\%, 2-sided level of significance, the estimated sample size was 151 subjects per group.

Baseline characteristics and related factors were analyzed by using descriptive statistics. Categorical variables were analyzed by using Chi-square test. Fisher's exact test was used for categorical data with a count of less than 5. All continuous data were tested for normality. Independent sample t-test and Mann-Whitney $U$ test were used to compare continuous variables, depending on the data distribution. The $p$-value $<0.05$ was considered statistical significance. Statistical analysis was performed by using SPSS for Windows version 18 software.

\section{Results}

302 patients were enrolled from the Siriraj hospital's database from October 2016 to October 2018; 151 patients in each group. The mean age of the total population was 80 years, and 43 (28.5\%) of subjects were $\geq 85$ years of age. Gender distribution, comorbidities, and the Charlson Comorbidity Index (CCI) between both groups were not statistically different. There was a higher proportion of dementia in the Fast-track group (37.1\%) compared to the PRE-fast track group (23.8\%) ( $p=$ 0.012). The mean BMI for patients in the PRE-fast track group was $21.9 \pm 4.14$ and $22.0 \pm 3.56 \mathrm{~kg} / \mathrm{m}^{2}$ in the Fasttrack group $(p=0.783)$ in Table 3 . There was no difference between groups in the hematocrit level, the white blood cell count and the serum albumin level. More than $80 \%$ of patients had the inadequate vitamin D level in both groups.

Patients in both groups had similar fracture types including femoral neck fractures and intertrochanteric fractures, which were the majority types. Almost all included patients underwent surgical treatment (93.4\% VS 94.0\% $p=1.000$ ) (Table 4). After the Fast-track program for Acute Geriatric Hip Fractures was implemented, $80.3 \%$ of patients had surgery within $72 \mathrm{~h}$ compared to $44.7 \%$ of those in the PRE-fast track group $(p<0.001)$. Ninety $(63.4 \%)$ of the Fast-track group had surgery within $48 \mathrm{~h}$ compared to 39 (27.7\%) of those in the PREfast track group $(\mathrm{p}<0.001)$ (Table 4$)$. With regard to the quality indicators for the implementation of the Fasttrack program for Acute Geriatric Hip Fractures, all structure indicators were successfully arranged. For process indicators, most indicators have been achieved at a higher proportion compared to that in the PRE-fast track group as shown in Tables 4 and 5 .

A higher proportion of patients in the Fast-track group obtained the ambulation program on the first postoperative day. The program included the range of motion exercise (ROM) and the ankle pumping. On the 3rd postoperative day, more than $50 \%$ of patients were able to stand or walk in the Fast-track group compared to only $31 \%$ of those in the PRE-fast track group in Table 5.

The proportion of participants with delirium at any point postoperatively was similar in both groups. The percentage of delirium in the PRE-fast track group and the Fast-track group were 34.0 and $31.0 \%$ respectively $(p=0.583)$ in Table 6. Other complications were similar in both groups. Importantly, there was a higher proportion of people diagnosis of dementia in the Fast-track group that may have contributed to clinical outcomes. Therefore, a stratified analysis by dementia status was performed, which revealed a nonsignificant trend toward reduced delirium after implementing the Fast-track program among patients with dementia in Table 7 .

The secondary outcomes were summarized in Table 8. The length of stay in the Fast-track group was significantly shorter (11 (8-17) VS 13 (9-18), $p=0.017)$. However, there was no significant difference between hospital mortality and long term mortality. Most patients in both groups were discharged to home. The readmission rates in both groups were similar. The information about the patients' function (Barthel index) 
Table 3 Baseline characteristics of included population

\begin{tabular}{|c|c|c|c|}
\hline & $\begin{array}{l}\text { PRE - fast track } \\
(n=151)\end{array}$ & $\begin{array}{l}\text { Fast-track } \\
(n=151)\end{array}$ & $P$ value \\
\hline Age, years, mean $\pm S D$ & $80.7 \pm 7.51$ & $79.7 \pm 7.85$ & 0.272 \\
\hline$\geq 85$ years, $n(\%)$ & $43(28.5)$ & $43(28.5)$ & 1.000 \\
\hline Female, n (\%) & $107(70.9)$ & $113(74.8)$ & 0.438 \\
\hline $\mathrm{BMI}, \mathrm{kg} / \mathrm{m} 2$, mean $\pm \mathrm{SD}$ & $21.89 \pm 4.14$ & $22.01 \pm 3.56$ & 0.783 \\
\hline$<18.5$ & $35(23.2)$ & $23(15.2)$ & 0.349 \\
\hline $18.5-22.9$ & $62(41.1)$ & $76(50.3)$ & \\
\hline $23.0-24.9$ & $20(13.2)$ & $21(13.9)$ & \\
\hline $25.0-29.9$ & $29(19.2)$ & $28(18.5)$ & \\
\hline$\geq 30$ & $5(3.3)$ & $3(2.0)$ & \\
\hline \multicolumn{4}{|l|}{ Comorbidities, n (\%) } \\
\hline Diabetes mellitus & $57(37.7)$ & $52(34.4)$ & 0.549 \\
\hline Hypertension & $120(79.5)$ & $119(78.8)$ & 0.887 \\
\hline Ischemic heart disease & $25(16.6)$ & $21(13.9)$ & 0.522 \\
\hline Congestive heart failure & $4(2.6)$ & $4(2.6)$ & 1.000 \\
\hline Cerebrovascular disease & $34(22.5)$ & $38(25.2)$ & 0.589 \\
\hline COPD, Bronchiectasis or Asthma & $9(6.0)$ & $5(3.3)$ & 0.274 \\
\hline CKD Stage 3-5 & $33(21.9)$ & $36(23.8)$ & 0.681 \\
\hline ESRD on HD/CAPD & $5(3.3)$ & $6(4.0)$ & 0.759 \\
\hline Dementia & $36(23.8)$ & $56(37.1)$ & 0.012 \\
\hline Charlson Comorbidity Index (CCI), n (\%) & & & 0.494 \\
\hline 2 & $7(4.6)$ & $6(4.0)$ & \\
\hline 3 & $10(6.6)$ & $18(11.9)$ & \\
\hline 4 & $38(25.2)$ & $28(18.5)$ & \\
\hline 5 & $26(17.2)$ & $34(22.5)$ & \\
\hline$\geq 6$ & $70(46.4)$ & $65(43.1)$ & \\
\hline Education, years, n (\%) & & & 0.479 \\
\hline$\leq 4$ & $95(62.9)$ & $89(58.9)$ & \\
\hline$>4$ & $56(37.1)$ & $62(41.1)$ & \\
\hline Polypharmacy, n (\%) & & & 0.120 \\
\hline$<5$ & $32(21.2)$ & $34(22.5)$ & \\
\hline $5-10$ & $64(42.4)$ & $76(50.3)$ & \\
\hline$>10$ & $55(36.4)$ & $41(27.2)$ & \\
\hline BADL, Dependent, n (\%) & $21(13.9)$ & $22(14.6)$ & 0.869 \\
\hline IADL, Dependent, n (\%) & $51(33.8)$ & $59(39.1)$ & 0.339 \\
\hline Hematocrit, \%, mean \pm SD & $34.71 \pm 6.02$ & $34.95 \pm 5.52$ & 0.711 \\
\hline WBC count, cell/mm3, mean \pm SD & $10,059.00 \pm 3306.11$ & $10,525.56 \pm 3686.88$ & 0.249 \\
\hline Serum albumin (pre-op), g/dl, mean \pm SD & $3.74 \pm 0.54$ & $3.76 \pm 0.50$ & 0.707 \\
\hline Vitamin D level, $\mathrm{ng} / \mathrm{mL}$, mean \pm SD $(n=284)$ & $\begin{array}{l}n=136 \\
18.38 \pm 9.84\end{array}$ & $\begin{array}{l}n=148 \\
19.36 \pm 9.42\end{array}$ & 0.393 \\
\hline$\geq 30$ & $16(11.8)$ & $18(12.2)$ & 0.211 \\
\hline $20-29^{a}$ & $31(22.8)$ & $47(31.8)$ & \\
\hline$<20^{\mathrm{b}}$ & $89(65.4)$ & $83(56.1)$ & \\
\hline
\end{tabular}

$B A D L$ Basic activities of daily living

$I A D L$ Instrumental activities of daily living

a vitamin $D$ insufficiency $20-29 \mathrm{ng} / \mathrm{mL}$

${ }^{b}$ vitamin $D$ deficiency $<20 \mathrm{ng} / \mathrm{mL}$ 
Table 4 Fracture type, time to surgery and consultation

\begin{tabular}{|c|c|c|c|}
\hline & $\begin{array}{l}\text { PRE - fast track } \\
(\mathrm{n}=151)\end{array}$ & $\begin{array}{l}\text { Fast-track } \\
(n=151)\end{array}$ & $P$ value \\
\hline Fracture Type, n (\%) & & & 0.725 \\
\hline Femoral neck fracture & $74(49.0)$ & $79(52.3)$ & \\
\hline Intertrochanteric fracture & $75(49.7)$ & $69(45.7)$ & \\
\hline Subtrochanteric fracture & $2(1.3)$ & $3(2.0)$ & \\
\hline Pathologic fracture, n (\%) & $1(0.7)$ & $1(0.7)$ & 1.000 \\
\hline Surgery, n (\%) & $141(93.4)$ & $142(94.0)$ & 1.000 \\
\hline Time to surgery ${ }^{\mathrm{a}}, \mathrm{n}(\%)(n=283)$ & & & $<0.001$ \\
\hline$\leq 24 \mathrm{~h}$ & $18(12.8)$ & $45(31.7)$ & \\
\hline $25-48 h$ & $21(14.9)$ & $45(31.7)$ & \\
\hline $49-72 \mathrm{~h}$ & $24(17.0)$ & $24(16.9)$ & \\
\hline$>72 \mathrm{~h}$ & $78(55.3)$ & $28(19.7)$ & \\
\hline \multicolumn{4}{|l|}{ Type of surgery, n (\%) $(n=283)$} \\
\hline Arthroplasty & $61(43.3)$ & $61(43.0)$ & \\
\hline Internal fixation & $78(55.3)$ & $81(57.0)$ & \\
\hline Others & $2(0.7)$ & $0(0.0)$ & \\
\hline \multicolumn{4}{|l|}{ Ward, n (\%) } \\
\hline General ward & $56(37.1)$ & $58(38.4)$ & 0.812 \\
\hline Consult Geriatrics, n (\%) & $145(96.0)$ & $151(100.0)$ & 0.030 \\
\hline \multicolumn{4}{|l|}{ Consult within 24 h., n (\%) } \\
\hline Geriatrics & $101(66.9)$ & $139(92.1)$ & $<0.001$ \\
\hline Acute pain service (APS) & $6(4.0)$ & $47(31.1)$ & $<0.001$ \\
\hline Physical therapists (PT) & $2(1.3)$ & $5(3.3)$ & 0.448 \\
\hline
\end{tabular}

at day 4, month 3 and month 12 after the operation was collected. The Barthel index of patients in both groups was subsequently improved after the patients were discharged to home, but there was no difference in the Barthel index between group in Table 8 .

\section{Discussion}

This study has demonstrated the outcome of implementation of a multidisciplinary team for caring of older

Table 5 Rehabilitation interventions (maximum capacity) on D1 and D3 after surgery

\begin{tabular}{lllll}
\hline & & $\begin{array}{l}\text { PRE } \text { fast track } \\
(\boldsymbol{n}=\mathbf{1 4 1})\end{array}$ & $\begin{array}{l}\text { Fast-track } \\
(\boldsymbol{n}=\mathbf{1 4 2})\end{array}$ & $\boldsymbol{P}$ value \\
\hline Day 1 & ROM/Ankle pumping & $16(11.3)$ & $28(19.7)$ & 0.144 \\
$\mathrm{n}(\%)$ & Side sitting & $28(19.9)$ & $37(26.0)$ & 0.446 \\
& Standing & $2(1.4)$ & $4(2.8)$ & 0.711 \\
& Walk & $12(8.5)$ & $18(12.7)$ & 0.511 \\
Day 3 & ROM/Ankle pumping & $3(2.1)$ & $6(4.2)$ & 0.586 \\
n (\%) & Side sitting & $16(11.3)$ & $22(15.5)$ & 0.576 \\
& Standing & $5(3.5)$ & $6(4.2)$ & 0.931 \\
& Walk & $39(27.6)$ & $66(46.5)$ & 0.005 \\
\hline
\end{tabular}

people with hip fractures in a large referral center university hospital in resource limited settings. The implementation was successful for accelerating the operation time and reducing length of stay. However, benefits on patient-centered outcomes were not demonstrated in this analysis contrast to several existing evidences [13, 34]. This finding might stem from several factors.

Outcomes including in-hospital complications after implementation of the Fast-track program for Acute Geriatric Hip Fractures were analyzed. There was no statistical difference in the incidence of delirium between before and after implementation of the program. Published studies reported reductions in post-operative medical complications, delirium and in-hospital mortality mainly occurring in settings with applied routine geriatric consultation [10, 12, 13, 17, 19, 21, 35, 36]. In Siriraj hospital, geriatric consultation was a common practice (96\%) before the Fast-track program for Acute Geriatric Hip Fractures was implemented. This may have contributed to the inability to detect important differences following implementation of the program. Moreover, the overall incidence of post-operative delirium in the study was approximately $32 \%$, lower than the 
Table 6 The primary outcomes

\begin{tabular}{|c|c|c|c|}
\hline & $\begin{array}{l}\text { PRE - fast track } \\
(n=151)\end{array}$ & $\begin{array}{l}\text { Fast-track } \\
(n=151)\end{array}$ & $P$ value \\
\hline Post-operative complication, n (\%) & $n=141$ & $n=142$ & \\
\hline Delirium & $48(34.0)$ & $44(31.0)$ & 0.583 \\
\hline Urinary tract infection & $21(14.9)$ & $30(21.1)$ & 0.173 \\
\hline Pressure injury/ IAD & $18(12.8)$ & $17(12.0)$ & 0.839 \\
\hline Pneumonia & $10(7.1)$ & $12(8.5)$ & 0.670 \\
\hline Stroke/TIA & $1(0.7)$ & $1(0.7)$ & 1.000 \\
\hline Myocardial infarction & $1(0.7)$ & $2(1.4)$ & 1.000 \\
\hline Deep vein thrombosis & $0(0.0)$ & $1(0.7)$ & 1.000 \\
\hline Pulmonary embolism & $0(0.0)$ & $1(0.7)$ & 1.000 \\
\hline Pain score $>4$ & $38(27.0)$ & $34(23.9)$ & 0.561 \\
\hline Anemia (Blood transfusion) & $72(51.1)$ & $73(51.4)$ & 0.954 \\
\hline Wound infection & $0(0.0)$ & $0(0.0)$ & - \\
\hline \multicolumn{4}{|l|}{ Delirium Type $(n=92), \mathrm{n}(\%)$} \\
\hline Hyperactive delirium & $36(75.0)$ & $34(77.3)$ & \\
\hline Hypoactive delirium & $5(10.4)$ & $0(0.0)$ & \\
\hline Mixed type & $7(14.6)$ & $10(22.7)$ & \\
\hline
\end{tabular}

$45 \%$ rate reported by a previous study in a similar Thai population [37] and lower than the rates reported by studies in other countries [10,38-41]. This might indicate that the geriatric consultation in the PRE-fast track era was a standard level of care for a decrease in delirium. The study has affirmed the geriatric consultation also playing an important role in delirium reduction in resource-limited countries.

The prevalence of dementia in this study was significantly higher in the Fast-track group (37.1\% VS 23.8\%, $p<0.012$ ) and higher than that reported by earlier studies $[12,35,37,40]$. Dementia is an established risk factor for post-operative complications and outcomes including delirium, rehabilitation achievement and functional outcomes after discharged [40, 42], so a post-hoc analysis according to dementia status was performed. The analysis revealed a non-significant trend of delirium reduction for patients in both groups, with dementia and without dementia, after the program was implemented. The incidence of pressure injury was also lower in the people living with dementia in the Fast-track group. This makes clinical sense because delirium and pressure injury may be a result of inadequate pain control and prolonged immobilization, commonly experienced in people living with dementia. The program with multidisciplinary team was designed to prevent these undesirable symptoms.

The incidences of pneumonia, urinary tract infection, and pressure injury were higher than those in the

Table 7 The primary outcomes stratified by dementia

\begin{tabular}{|c|c|c|c|c|c|c|}
\hline & \multicolumn{3}{|c|}{ Dementia } & \multicolumn{3}{|c|}{ Non-Dementia } \\
\hline & PRE - FT & FT & $P$ value & PRE - FT & FT & $P$ value \\
\hline \multicolumn{7}{|c|}{ Post-operative complication, n (\%) } \\
\hline Delirium & $25(78.1)$ & $29(58.0)$ & 0.061 & $23(21.1)$ & $15(16.3)$ & 0.387 \\
\hline Pneumonia & $3(9.4)$ & $5(10.0)$ & 0.926 & $7(6.4)$ & $7(7.6)$ & 0.742 \\
\hline Urinary tract infection & $9(28.1)$ & $16(32.0)$ & 0.710 & $12(11.0)$ & $14(15.2)$ & 0.376 \\
\hline Pressure injury/ IAD & $7(21.9)$ & $7(14.0)$ & 0.355 & $11(10.1)$ & $10(10.9)$ & 0.857 \\
\hline Stroke/TIA & $0(0.0)$ & $1(2.0)$ & 0.421 & $1(0.9)$ & $0(0.0)$ & 0.357 \\
\hline Myocardial infarction & $1(3.1)$ & $1(2.0)$ & 0.747 & $0(0.0)$ & $1(1.1)$ & 0.275 \\
\hline Deep vein thrombosis & $0(0.0)$ & $1(2.0)$ & 0.421 & $0(0.0)$ & $0(0.0)$ & - \\
\hline Pulmonary embolism & $0(0.0)$ & $1(2.0)$ & 1.000 & $0(0.0)$ & $0(0.0)$ & - \\
\hline Pain score $>4$ & $6(18.8)$ & $10(20.0)$ & 0.889 & $32(29.4)$ & $24(26.1)$ & 0.606 \\
\hline Anemia (Blood transfusion) & $19(59.4)$ & $31(62.0)$ & 0.812 & $53(48.6)$ & $42(45.7)$ & 0.674 \\
\hline
\end{tabular}


Table 8 The secondary outcomes

\begin{tabular}{|c|c|c|c|}
\hline & $\begin{array}{l}\text { PRE - Fast track } \\
(n=151)\end{array}$ & $\begin{array}{l}\text { Fast-track } \\
(n=151)\end{array}$ & $P$ value \\
\hline Re - operation, n (\%) & $1(0.7)$ & $2(1.4)$ & 1.000 \\
\hline Length of stay, Median (25-75) & $13(9.75-18)$ & $11(8-17)$ & 0.017 \\
\hline In-hospital mortality, n (\%) & $5(3.3)$ & $4(2.6)$ & 0.735 \\
\hline Discharge ambulation status, $\mathrm{n}(\%)$ & & & 0.326 \\
\hline Wheelchair & $25(17.1)$ & $31(27.1)$ & \\
\hline Walker & $112(76.7)$ & $112(76.2)$ & \\
\hline Crutch & $2(1.4)$ & $0(0.0)$ & \\
\hline Unable to ambulate & $7(4.8)$ & $4(2.7)$ & \\
\hline Destination of discharge, n (\%) & & & 0.223 \\
\hline Home & $143(97.9)$ & $144(98.0)$ & \\
\hline Nursing home & $1(0.7)$ & $3(2.0)$ & \\
\hline Refer & $2(1.4)$ & $0(0.0)$ & \\
\hline Re - admission in 1 yr., $\mathrm{n}(\%)$ & $n=146$ & $n=147$ & 0.445 \\
\hline$\leq 90$ days & $9(6.1)$ & $15(10.2)$ & \\
\hline$>90$ days & $18(12.3)$ & $20(13.6)$ & \\
\hline \multicolumn{4}{|l|}{ Mortality, n (\%) } \\
\hline 3 months & $8(5.3)$ & $9(6.0)$ & 0.803 \\
\hline 6 months & $12(7.9)$ & $16(10.6)$ & 0.427 \\
\hline 1 year & $14(9.3)$ & $20(13.2)$ & 0.275 \\
\hline \multicolumn{4}{|c|}{ Function (Barthel index), Median (25-75) } \\
\hline Post op day $4(n=275)$ & $45(25.00-66.25)$ & $50(30.00-60.00)$ & 0.617 \\
\hline 3 months $(n=250)$ & $80(65.00-95.00)$ & $90(65.00-100.00)$ & 0.100 \\
\hline 12 months $(n=264)$ & $90(65.00-100.00)$ & $100(65.00-100.00)$ & 0.066 \\
\hline
\end{tabular}

previous studies $[13,17,43]$ and were not reduced after the Fast-track program for Acute Geriatric Hip Fractures had been implemented. Early ambulation is considered one of the most valuable postoperative strategies to reduce postoperative pneumonia and pressure injury [26, 44]. Early ambulation remained suboptimal, although was more common in the Fast-track group, but the statistically significant reductions in post-surgical complications were not observed. Barriers could possibly stem from the attitudes of involved healthcare staff, availability of therapists, or the patients' condition. A more comprehensive plan of barrier reduction from all involved parties with more practical strategies to apply the ambulation program might improve engagement and outcomes.

Moreover, during the first few months of the Fasttrack program for Acute Geriatric Hip Fractures, the APS team did not fully operate and some patients might not obtain the optimal pain control. Complications such as delirium and inadequate rehabilitation were also more common before the APS was fully implemented.

Hip fractures in older people affect short term mobility and long term functional outcomes [45-47]. The functional outcomes were measured by using the Barthel index. Although, there was no significant difference in the Barthel index for all comparisons between groups but there was a trend toward better function in the Fasttrack group. Moreover, most patients achieved improved functional outcomes over time and the majority reached full mobility at 1 year, which has been better results than other study [48]. Discharge destination might contribute to functional status of the patients. In other studies, most of the patients were discharged to institutional care units while most of the patients in this study were discharged back to home because of cultural norms for care of older people in Thailand. After discharged to home, the patients were looked after by dedicated family, which could contribute to better functional outcomes.

Debate on time to surgery for hip fracture surgery remains, not for the benefit of expedited surgery but rather the optimal time of how fast the time should be [23, 49, 50]. Most studies appear to indicate the 'optimal time' at $48 \mathrm{~h}$ following the cut off points utilized in metaanalyses [50]. Some important difficult-to-measure confounding factors might be the patients' risk for experiencing medical complications and other negative clinical 
consequences and the accompanied care provided in different settings. Patients included in the study, conducted in a large referral center, have more co-morbidities with higher Charlson comorbidity index compared to previous studies $[17,51]$. However, in this study, there was a similar rate of medical complications for the whole cohort compared to other studies in other settings. This might be one reason why we could not demonstrate the difference in primary outcome as we have reached the ceiling for reducing some complications. Accordingly, there were rooms for improving the program shown in the results. The rate of involvement of main specialties in the program remain low in some context and might contribute to the results observed. In the present cohort, the decisions to undergo surgery were based on agreement of all involved specialists for each patient. The delayed time to surgery might be to optimize medical conditions for the patients. To achieve the ultimate goal for the Fast-track program for Acute Geriatric Hip Fractures, we should focus on the orchestrating implementation of all involved disciplines, as well.

\section{Strengths and limitations}

Our study has several strengths. Data for this study was collected from several sources, including a prospective registry (FLS) allowing us to monitor several long-term outcomes such as functional status and quality of life. Data regarding related medical complications and possible interventions were thoroughly explored to identify the gap of practice. The selection of consecutive cases would reduce the selection bias for this study. Limitations of the study are mainly stemmed from its retrospective design. The retrieval of information from medical records might underestimate some interventions and complications. Delirium ascertainment is one important limitation as it is usually under-recognized and there was no routine delirium screening in the hospital. Nevertheless, several measurements were taken to ensure that most cases of delirium could be identified. Several interventions such as physiotherapy program could be underestimated. Moreover, this is a single center study in a university hospital, the generalizability of the results might be an issue.

\section{Conclusion}

We demonstrated the feasibility of the implementation of the comprehensive multidisciplinary care team in Siriraj hospital, a large referral center and a university hospital with complex administrative structures in resourcelimited setting. The Fast-track program for Acute Geriatric Hip Fractures reduced the length of hospital stay and time to surgery. Moreover, there was no increase in medical complications. However, several interventions in the program were not implemented as planned. A better embarking rate of all interventions might improve the mortality rate in this group of population.

\section{Acknowledgements}

The authors thank Ms. Wararat Boonnasa, Nurse coordinator of the Fracture liaison service for her assistance with data collection and Ms. Khemajira Karaketklang, BSc (nursing), M.P.H., for her contribution to the statistical analysis.

\section{Authors' contributions}

US, VS contributed to the study design, concept of this work, interpretation of data, and approval for final version of the article. TT, AU and DT

contributed to the concept of this study and approval for the final version of the article. All authors have read and approved the manuscript.

\section{Funding}

This research project was supported by Faculty of Medicine Siriraj Hospital, Mahidol University, Grant Number (IO) R016231051. The funding body played no role in the design of the study, the collection, analysis or interpretation of the data or the writing of this manuscript.

\section{Availability of data and materials}

The datasets used and/or analysed the current study are available from the corresponding author on reasonable request.

\section{Declarations}

Ethics approval and consent to participate

Approval of the research protocol was obtained from Siriraj Institutional Review Board (SIRB) (reference number Si 411/2019). Providing this study was a retrospective study, the SIRB considered the protocol as an expedited category and the inform consent from participants were not required according to SIRB standard operational procedures. The SIRB is grounded in foundational ethical principles embodied in the Declaration of Helsinki of 1964 and its subsequent revisions and the Belmont Report.

\section{Consent for publication}

Not applicable.

\section{Competing interests}

The authors declare that they have no competing interests.

\section{Author details}

'Department of Medicine, Division of Geriatric Medicine, Faculty of Medicine Siriraj Hospital, Mahidol University, Bangkok, Thailand. ${ }^{2}$ Department of Orthopedic Surgery, Faculty of Medicine Siriraj Hospital, Mahidol University, Bangkok, Thailand.

Received: 20 May 2021 Accepted: 22 September 2021

Published online: 12 October 2021

\section{References}

1. Wajanavisit W, Woratanarat P, Sawatriawkul S, Lertbusayanukul C, Ongphiphadhanakul B. Cost-utility analysis of osteoporotic hip fractures in Thais. J Med Assoc Thailand = Chotmaihet thangphaet. 2015;98 Suppl 8: S65-9.

2. Roberts KC, Brox WT, Jevsevar DS, Sevarino K. Management of hip fractures in the elderly. J Am Acad Orthopaed Surg. 2015;23(2):131-7. https://doi. org/10.5435/JAAOS-D-14-00432.

3. Cooper C, Campion G, Melton LJ 3rd. Hip fractures in the elderly: a worldwide projection. Osteopor Int. 1992;2(6):285-9. https://doi.org/10.1007/BF01 623184.

4. Cheng SY, Levy AR, Lefaivre KA, Guy P, Kuramoto L, Sobolev BJOI. Geographic trends in incidence of hip fractures: a comprehensive literature review. 2011;22(10):2575-86. https://doi.org/10.1007/s00198-011-1596-z.

5. Bhandari M, Swiontkowski M. Management of acute hip fracture. 2017; 377(21):2053-62. https://doi.org/10.1056/NEJMcp1611090.

6. Kanis JA, Odén A, McCloskey EV, Johansson H, Wahl DA, Cooper C, et al. A systematic review of hip fracture incidence and probability of fracture worldwide. Osteopor Int. 2012;23(9):2239-56. https://doi.org/10.1007/s001 98-012-1964-3. 
7. Kannegaard PN, van der Mark S, Eiken P, Abrahamsen B. Excess mortality in men compared with women following a hip fracture. National analysis of comedications, comorbidity and survival. Age Ageing. 2010;39(2):203-9. https://doi.org/10.1093/ageing/afp221.

8. Sambrook P, Cooper C. Osteoporosis. Lancet. 2006;367(9527):2010-8. https:// doi.org/10.1016/S0140-6736(06)68891-0.

9. Khan R, Fernandez C, Kashifl F, Shedden R, Diggory P. Combined orthogeriatric care in the management of hip fractures: a prospective study. Ann R Coll Surg Engl. 2002;84(2):122-4.

10. Marcantonio ER, Flacker JM, Wright RJ, Resnick NM. Reducing delirium after hip fracture: a randomized trial. J Am Geriatr Soc. 2001;49(5):516-22. https:// doi.org/10.1046/j.1532-5415.2001.49108.x.

11. Gruber-Baldini AL, Zimmerman S, Morrison RS, Grattan LM, Hebel JR, Dolan $\mathrm{MM}$, et al. Cognitive impairment in hip fracture patients: timing of detection and longitudinal follow-up. J Am Geriatr Soc. 2003;51(9):1227-36. https:// doi.org/10.1046/j.1532-5415.2003.51406.x.

12. Vidan M, Serra JA, Moreno C, Riquelme G, Ortiz J. Efficacy of a comprehensive geriatric intervention in older patients hospitalized for hip fracture: a randomized, controlled trial. J Am Geriatr Soc. 2005;53(9):1476-82. https://doi.org/10.1111/j.1532-5415.2005.53466.x.

13. Fisher AA, Davis MW, Rubenach SE, Sivakumaran S, Smith PN, Budge MM. Outcomes for older patients with hip fractures: the impact of orthopedic and geriatric medicine cocare. J Orthop Trauma. 2006;20(3):172-8discussion 9-80. https://doi.org/10.1097/01.bot.0000202220.88855.16.

14. Smektala R, Endres HG, Dasch B, Maier C, Trampisch HJ, Bonnaire F, et al. The effect of time-to-surgery on outcome in elderly patients with proximal femoral fractures. BMC Musculoskelet Disord. 2008;9(1):171. https://doi.org/1 0.1186/1471-2474-9-171.

15. Kammerlander C, Roth T, Friedman SM, Suhm N, Luger TJ, KammerlanderKnauer $U$, et al. Ortho-geriatric service--a literature review comparing different models. Osteopor Int. 2010;21(Suppl 4):S637-46. https://doi.org/1 0.1007/s00198-010-1396-x.

16. Dhanwal DK, Dennison EM, Harvey NC, Cooper C. Epidemiology of hip fracture: worldwide geographic variation. Indian J Orthop. 2011;45(1):15-22. https://doi.org/10.4103/0019-5413.73656.

17. Borges FK, Bhandari M, Guerra-Farfan E, et al. Accelerated surgery versus standard care in hip fracture (HIP ATTACK): an international, randomised, controlled trial. Lancet. 2020;395(10225):698-708.

18. Moyet J, Deschasse G, Marquant B, Mertl P, Bloch F. Which is the optimal orthogeriatric care model to prevent mortality of elderly subjects post hip fractures? A systematic review and meta-analysis based on current clinical practice. Int Orthop. 2018;43(6):1449-54. https://doi.org/10.1007/s00264-01 8-3928-5.

19. Shields L, Henderson V, Caslake R. Comprehensive geriatric assessment for prevention of delirium after hip fracture: a systematic review of randomized controlled trials. J Am Geriatr Soc. 2017;65(7):1559-65. https://doi.org/1 $0.1111 /$ jgs. 14846

20. Eamer G, Taheri A, Chen SS, Daviduck Q, Chambers T, Shi X, et al. Comprehensive geriatric assessment for older people admitted to a surgical service. Cochr Database Syst Rev. 2018;1:Cd012485

21. Pajulammi HM, Pihlajamaki HK, Luukkaala TH, Jousmaki JJ, Jokipii PH, Nuotio MS. The effect of an in-hospital comprehensive geriatric assessment on short-term mortality during Orthogeriatric hip fracture program-which patients benefit the Most? Geriatr Orthopaed Surg Rehabil. 2017:8(4):183-91. https://doi.org/10.1177/2151458517716516.

22. Prestmo A, Hagen G, Sletvold O, Helbostad JL, Thingstad P, Taraldsen K, et al. Comprehensive geriatric care for patients with hip fractures: a prospective, randomised, controlled trial. Lancet (London, England). 2015; 385(9978):1623-33.

23. Klestil T, Röder C, Stotter C, Winkler B, Nehrer S, Lutz M, et al. Impact of timing of surgery in elderly hip fracture patients: a systematic review and meta-analysis. Sci Rep. 2018;8(1):13933.

24. Asplin G, Carlsson G, Zidén L, Kjellby-Wendt G. Early coordinated rehabilitation in acute phase after hip fracture - a model for increased patient participation. BMC Geriatr. 2017;17(1):240.

25. Hip fracture: management. London: National Institutes for Health and Care Excellence J; 2011. https://www.nice.org.uk/guidance/cg124

26. Warren J, Sundaram K, Anis H, McLaughlin J, Patterson B, Higuera CA, et al. The association between weight-bearing status and early complications in hip fractures. Eur J Orthop Surg Traumatol. 2019;29(7):1419-27. https://doi. org/10.1007/s00590-019-02453-z.
27. Prasartkul P. Situation of the thai elderly 2016, National Economic and Social Development Board (NESDB),Population Projection in Thailand: 2010-2040. 2016.

28. Dawson L, Klingman KL, Marrazzo J. Addressing standards of care in resource-limited settings. J Acquir Immune Defic Syndr. 2014;65 Suppl 1(0 1):S10-4.

29. Country Diagnostic Study on Long-Term Care in Thailand. Available from: https://doi.org/10.22617/TCS200373-2. Accessed 30 Mar 2021.

30. Care WHOloH-BL-T. Community home-based care in resource-limited settings : a framework for action. Geneva: World Health Organization; 2002.

31. Suhm N, Kaelin R, Studer P, Wang Q, Kressig RW, Rikli D, et al. Orthogeriatric care pathway: a prospective survey of impact on length of stay, mortality and institutionalisation. Arch Orthop Trauma Surg. 2014;134(9):1261-9. https://doi.org/10.1007/s00402-014-2057-x.

32. Choong PF, Langford AK, Dowsey MM, Santamaria NM. Clinical pathway for fractured neck of femur: a prospective, controlled study. Med J Aust. 2000; 172(9):423-6. https://doi.org/10.5694/j.1326-5377.2000.tb124038.x.

33. Roberts HC, Pickering RM, Onslow E, Clancy M, Powell J, Roberts A, et al. The effectiveness of implementing a care pathway for femoral neck fracture in older people: a prospective controlled before and after study. Age Ageing. 2004;33(2):178-84. https://doi.org/10.1093/ageing/afh063.

34. Friedman SM, Mendelson DA, Bingham KW, Kates SL. Impact of a Comanaged geriatric fracture center on short-term hip fracture outcomes. Arch Intern Med. 2009;169(18):1712-7. https://doi.org/10.1001/a rchinternmed.2009.321.

35. Deschodt M, Braes T, Flamaing J, Detroyer E, Broos P, Haentjens $P$, et al. Preventing delirium in older adults with recent hip fracture through multidisciplinary geriatric consultation. J Am Geriatr Soc. 2012;60(4):733-9. https://doi.org/10.1111/j.1532-5415.2012.03899.x

36. Leung AH, Lam TP, Cheung WH, Chan T, Sze PC, Lau T, et al. An orthogeriatric collaborative intervention program for fragility fractures: a retrospective cohort study. J Trauma. 2011;71(5):1390-4. https://doi.org/10.1 097/TA.0b013e31821f7e60.

37. Muangpaisan W, Wongprikron A, Srinonprasert V, Suwanpatoomlerd S, Sutipornpalangkul W, Assantchai P. Incidence and risk factors of acute delirium in older patients with hip fracture in Siriraj hospital. J Med Assoc Thailand Chotmaihet thangphaet. 2015:98(4):423-30.

38. Berggren D, Gustafson Y, Eriksson B, Bucht G, Hansson LI, Reiz S, et al. Postoperative confusion after anesthesia in elderly patients with femoral neck fractures. Anesth Analg. 1987;66(6):497-504. https://doi.org/10.1213/ 00000539-198706000-00003.

39. Gilchrist WJ, Newman RJ, Hamblen DL, Williams BO. Prospective randomised study of an orthopaedic geriatric inpatient service. BMJ (Clinical research ed). 1988;297(6656):1116-8. https://doi.org/10.1136/bmj.297.6656.1116.

40. Mosk CA, Mus M, Vroemen JP, van der Ploeg T, Vos DI, Elmans LH, et al. Dementia and delirium, the outcomes in elderly hip fracture patients. Clin Interv Aging. 2017;12:421-30. https://doi.org/10.2147/CIA.S115945.

41. Watne LO, Torbergsen AC, Conroy S, Engedal K, Frihagen F, Hjorthaug GA, et al. The effect of a pre- and postoperative orthogeriatric service on cognitive function in patients with hip fracture: randomized controlled trial (Oslo Orthogeriatric trial). BMC Med. 2014;12(1):63. https://doi.org/10.1186/1741-7015-12-63.

42. Kassahun WT. The effects of pre-existing dementia on surgical outcomes in emergent and nonemergent general surgical procedures: assessing differences in surgical risk with dementia. BMC Geriatr. 2018;18(1):153.

43. Lawrence VA, Hilsenbeck SG, Noveck H, Poses RM, Carson JL. Medical complications and outcomes after hip fracture repair. Arch Intern Med. 2002;162(18):2053-7. https://doi.org/10.1001/archinte.162.18.2053.

44. Pashikanti L, Von Ah D. Impact of early mobilization protocol on the medicalsurgical inpatient population: an integrated review of literature. Clin Nurse Spec. 2012;26(2):87-94. https://doi.org/10.1097/NUR.0b013e31824590e6.

45. Makridis KG, Karachalios T, Kontogeorgakos VA, Badras LS, Malizos KN. The effect of osteoporotic treatment on the functional outcome, re-fracture rate, quality of life and mortality in patients with hip fractures: a prospective functional and clinical outcome study on 520 patients. Injury. 2015;46(2): 378-83. https://doi.org/10.1016/j.injury.2014.11.031.

46. Kammerlander C, Gosch M, Kammerlander-Knauer U, Luger TJ, Blauth M, Roth T. Long-term functional outcome in geriatric hip fracture patients. Arch Orthop Trauma Surg. 2011;131(10):1435-44. https://doi.org/10.1007/ s00402-011-1313-6.

47. de Joode SGCJ, Kalmet PHS, Fiddelers AAA, Poeze M, Blokhuis TJ. Long-term functional outcome after a low-energy hip fracture in elderly patients. J Orthop Traumatol. 2019;20(1):20. 
48. Bliemel C, Buecking B, Oberkircher L, Knobe M, Ruchholtz S, Eschbach D. The impact of pre-existing conditions on functional outcome and mortality in geriatric hip fracture patients. Int Orthop. 2017;41(10):1995-2000. https:// doi.org/10.1007/s00264-017-3591-2.

49. Shiga T, Wajima Z, Ohe Y. Is operative delay associated with increased mortality of hip fracture patients? Systematic review, meta-analysis, and meta-regression. Can J Anaesth. 2008;55(3):146-54. https://doi.org/10.1007/ BF03016088.

50. Lewis PM, Waddell JP. When is the ideal time to operate on a patient with a fracture of the hip? : A review of the available literature. Bone Joint J. 2016;98-b(12):1573-81.

51. Yoo J, Lee JS, Kim S, Kim BS, Choi H, Song DY, et al. Length of hospital stay after hip fracture surgery and 1-year mortality. Osteopor Int. 2018;30(1):14553. https://doi.org/10.1007/s00198-018-4747-7.

\section{Publisher's Note}

Springer Nature remains neutral with regard to jurisdictional claims in published maps and institutional affiliations.

Ready to submit your research? Choose BMC and benefit from:

- fast, convenient online submission

- thorough peer review by experienced researchers in your field

- rapid publication on acceptance

- support for research data, including large and complex data types

- gold Open Access which fosters wider collaboration and increased citations

- maximum visibility for your research: over $100 \mathrm{M}$ website views per year

At $\mathrm{BMC}$, research is always in progress.

Learn more biomedcentral.com/submissions 